Article

\title{
Identification of Targetable Lesions in Anaplastic Thyroid Cancer by Genome Profiling
}

\author{
Naveen Ravi ${ }^{1}$, Minjun Yang ${ }^{1}{ }^{\mathbb{D}}$, Sigurdur Gretarsson ${ }^{2}$, Caroline Jansson ${ }^{1}$, Nektaria Mylona ${ }^{3}$, \\ Saskia R. Sydow ${ }^{1}$, Eleanor L. Woodward ${ }^{1}$, Lars Ekblad ${ }^{3}$, Johan Wennerberg ${ }^{2}$ and \\ Kajsa Paulsson $1, *$ (D) \\ 1 Department of Laboratory Medicine, Division of Clinical Genetics, Lund University, \\ SE-221 84 Lund, Sweden; naveen.ravi@med.lu.se (N.R.); Minjun.yang@med.lu.se (M.Y.); \\ Caroline.jansson@med.lu.se (C.J.); Saskia.sydow@med.lu.se (S.R.S.); Eleanor.woodward@med.lu.se (E.L.W.) \\ Division of Otorhinolaryngology/Head and Neck Surgery, Clinical Sciences, Lund University and Skåne \\ University Hospital, SE-221 85 Lund, Sweden; stg72@live.com (S.G.); Johan.wennerberg@med.lu.se (J.W.) \\ 3 Division of Oncology and Pathology, Clinical Sciences, Lund University and Skåne University Hospital, \\ SE-221 85 Lund, Sweden; Nektaria.mylona@skane.se (N.M.); Lars.Ekblad@med.lu.se (L.E.) \\ * Correspondence: kajsa.paulsson@med.lu.se; Tel.: +46-46-222-69-95
}

Received: 13 February 2019; Accepted: 19 March 2019; Published: 22 March 2019

\begin{abstract}
Anaplastic thyroid cancer (ATC) is a rare and extremely malignant tumor with no available cure. The genetic landscape of this malignancy has not yet been fully explored. In this study, we performed whole exome sequencing and the RNA-sequencing of fourteen cases of ATC to delineate copy number changes, fusion gene events, and somatic mutations. A high frequency of genomic amplifications was seen, including $29 \%$ of cases having amplification of CCNE1 and $9 \%$ of CDK6; these events may be targetable by cyclin dependent kinase (CDK) inhibition. Furthermore, $9 \%$ harbored amplification of TWIST1, which is also a potentially targetable lesion. A total of 21 fusion genes in five cases were seen, none of which were recurrent. Frequent mutations included TP53 (55\%), the TERT promoter (36\%), and ATM (27\%). Analyses of mutational signatures showed an involvement of processes that are associated with normal aging, defective DNA mismatch repair, activation induced cytidine deaminase (AID)/apolipoprotein B editing complex (APOBEC) activity, failure of DNA double-strand break repair, and tobacco exposure. Taken together, our results shed new light on the tumorigenesis of ATC and show that a relatively large proportion (36\%) of ATCs harbor genetic events that make them candidates for novel therapeutic approaches. When considering that ATC today has a mortality rate of close to $100 \%$, this is highly relevant from a clinical perspective.
\end{abstract}

Keywords: anaplastic thyroid cancer; whole exome sequencing; RNA-sequencing; formalin-fixed paraffin embedded tissues; fusion genes; somatic mutations; copy number alterations; CCNE1

\section{Introduction}

Anaplastic thyroid cancer (ATC) is an extremely aggressive tumor, with close to $100 \%$ mortality and no available cure [1-4]. The lack of curative treatments for ATC makes it important to understand the underlying tumorigenesis of this disease; however, the genomic landscape of ATC has not yet been fully delineated.

Cytogenetic analysis and array comparative genome hybridization (aCGH) of ATC has revealed high levels of aneuploidy, with chromosome numbers ranging from 65-120; however, these studies were performed on small cohorts of samples [5-11]. Recently, Pozdeyev et al. found amplifications involving KIT in 4q12 (4\% of cases), CCNE1 in 19q12 (4\% of cases) and CD274 (previously PD-L1), PDCD1LG2 (previously PD-L2), and JAK2 in 9p24 (3\% of cases) using targeted sequencing. As regards 
to structural rearrangements, a STRN-ALK translocation has been found in one case of ATC [12], but no recurrent gene fusions have been identified. Genes that are recurrently mutated in ATC include TP53 (25-60\% of cases), BRAF (25-90\%), USH2A (20\%), NRAS (15-20\%), PTEN (15\%), NF1 (10-35\%), PIK3CA (10-20\%), EIF1AX (10\%), ATM (8\%), HRAS (7\%), KRAS (5-10\%), and CTNNB1 (5\%) [13-22]. Furthermore, TERT promoter mutations, leading to TERT expression, are seen in $15-75 \%$ of cases $[13,17,18,21-23]$.

Most next generation sequencing studies of ATC have been done by targeted sequencing of custom gene panels [13-19]. In total, only 41 primary ATCs that were investigated with whole exome seuencing (WES) have been previously published [20,21,24], and no RNA-sequencing (RNA-seq) that is aimed at fusion gene detection is available in the literature. As the genomic landscape of ATC has thus not yet been fully explored, we applied WES and RNA-seq on primary tumor samples to identify the novel genetic events that contribute to ATC tumorigenesis and that may be used as therapeutic targets.

\section{Results}

\subsection{Genomic Amplifications Are Common in ATC}

Copy number analysis could be undertaken based on WES data in 10 cases (Table 1). Seven of the analyzed cases had large variations in chromosome copy number, as well as variant allele frequencies (VAFs) that were suggestive of polyploidy, whereas three appeared to have near-diploid genomes (Figure 1a, Table S1). A median of 16 breakpoints, defined as a change in copy number state, were detected per case (range $5-43)$, with a high proportion $(31 / 187 ; 17 \%)$ of breakpoints occurring in centromeres; all of the cases had at least one breakpoint in a centromere (range 1-7; Figure 1b, Table S1). Chromosome 8 displayed a pattern of loss of $8 p$ and concurrent gain of $8 q$, with breakpoints in the centromere in six cases $(60 \%)$, possibly indicating isochromosome $8 \mathrm{q}$. Two additional cases had gain of the whole chromosome 8 , making gain of $8 \mathrm{q}$ present in 8/10 (80\%) investigated cases (Table S1).

Table 1. Clinical data and genetic analyses of 14 cases of primary anaplastic thyroid cancer.

\begin{tabular}{|c|c|c|c|c|c|c|c|c|c|c|c|}
\hline $\begin{array}{l}\text { Case } \\
\text { No. }\end{array}$ & Gender & Age & Tumor Size (cm) & $\mathbf{T}$ & $\mathbf{N}$ & $\mathbf{M}$ & Stage & $\begin{array}{c}\text { Ki67 } \\
(\%)\end{array}$ & $\begin{array}{c}\text { Copy } \\
\text { Number } \\
\text { Analysis }\end{array}$ & $\begin{array}{l}\text { Fusion } \\
\text { Gene } \\
\text { Analysis }\end{array}$ & $\begin{array}{c}\text { Mutation } \\
\text { Analysis } \\
\text { (Matched } \\
\text { Normal) }\end{array}$ \\
\hline 2 & M & 70 & $6 \times 8$ & $\mathrm{~T} 4 \mathrm{a}$ & No & M0 & IV A & 35 & Yes & Yes & Yes (yes) \\
\hline 3 & $\mathrm{~F}$ & 73 & $8 \times 6 \times 5$ & $\mathrm{~T} 4 \mathrm{~b}$ & $\mathrm{~N} 1 \mathrm{~b}$ & M0 & IV B & 75 & Yes & Yes & Yes (no) \\
\hline 4 & M & 64 & $4.6 \times 4.3 \times 7.4$ & $\mathrm{~T} 4 \mathrm{~b}$ & N0 & M0 & IV B & 90 & Yes & No & Yes (yes) \\
\hline 7 & $\mathrm{~F}$ & 74 & $6 \times 10 \times 7$ & $\mathrm{~T} 4 \mathrm{~b}$ & N1 & M1 & IV C & $\mathrm{N} / \mathrm{A}$ & Yes & Yes & Yes (yes) \\
\hline 8 & $\mathrm{~F}$ & 84 & $11.9 \times 8.3 \times 11.7$ & pT4b & $\mathrm{pN} 1 \mathrm{~b}$ & pM1 & IV C & 50 & Yes & Yes & Yes (yes) \\
\hline 9 & $\mathrm{~F}$ & 86 & $7 \times 5.5 \times 4.5$ & pT4b & No & M1 & IV C & $\mathrm{N} / \mathrm{A}$ & Yes & Yes & Yes (no) \\
\hline 10 & $\mathrm{~F}$ & 70 & $5 \times 3.5 \times 5$ & $\mathrm{~T} 4 \mathrm{~b}$ & No & M0 & IV B & 50 & No & Yes & No \\
\hline 11 & M & 84 & $8.5 \times 6.5 \times 5.5$ & $\mathrm{~T} 4 \mathrm{~b}$ & No & M1 & IV C & $\mathrm{N} / \mathrm{A}$ & Yes & Yes & Yes (yes) \\
\hline 12 & M & 49 & $7 \times 7 \times 5$ & $\mathrm{~T} 4 \mathrm{~b}$ & No & M0 & IV B & $\mathrm{N} / \mathrm{A}$ & No & Yes & Yes (yes) \\
\hline
\end{tabular}

N/A, data not available; T: size/extent of primary tumor; N, degree of spreading to regional lymph nodes; M, presence or absence of distant metastasis. TNM staging according to Sobin et al [25]. 
a<smiles>[10BH][13CH]C</smiles>

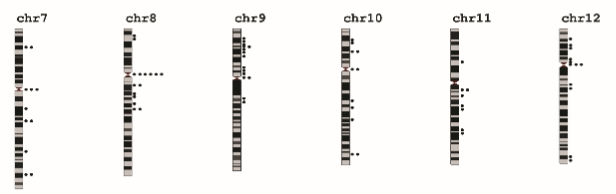

.hr13
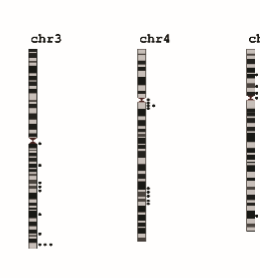

$\underbrace{\text { chr15 }}$

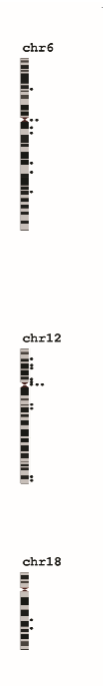

b
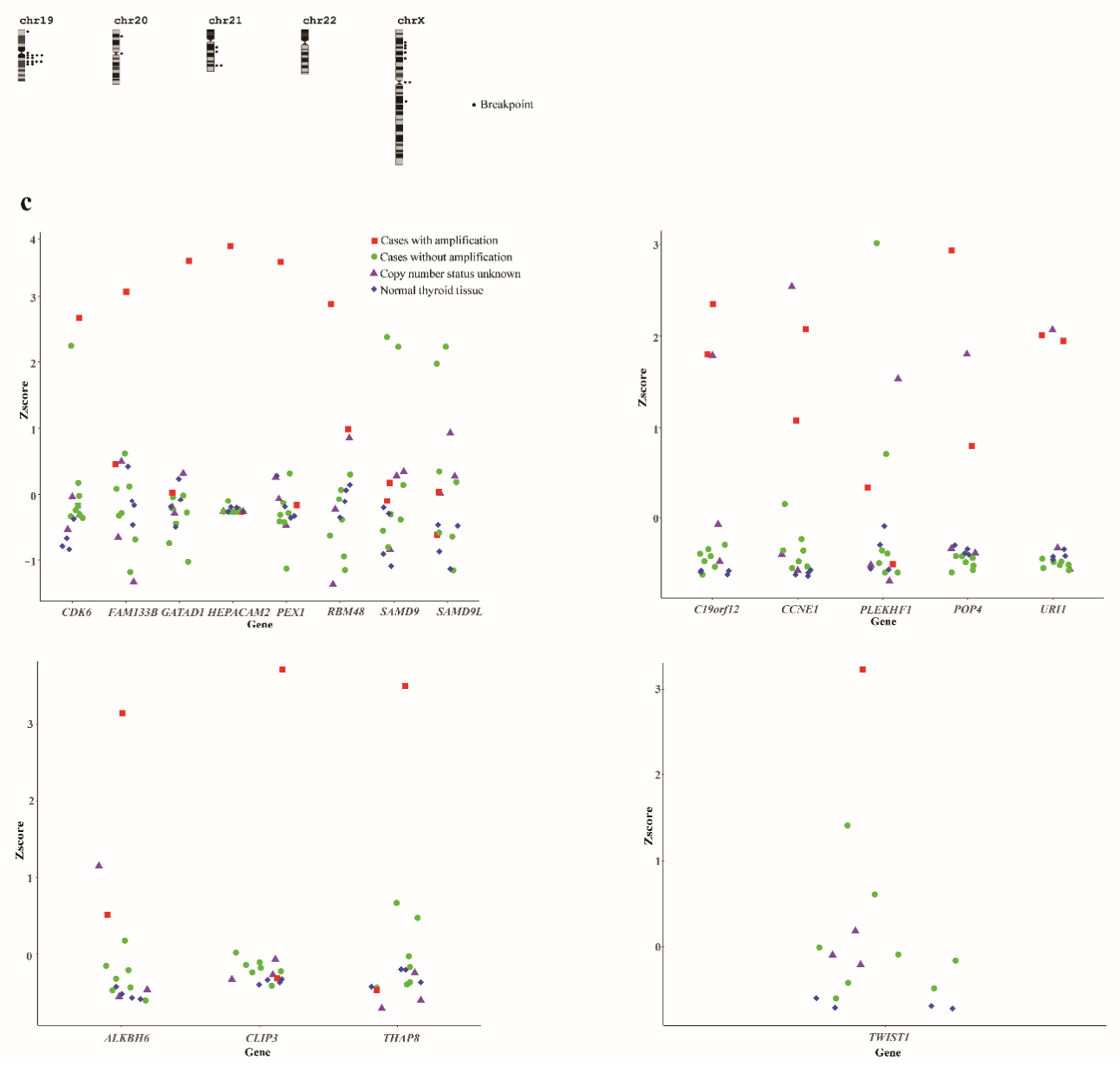

Figure 1. Detection of copy number variants in anaplastic thyroid cancer (ATC). (a) Breakpoint map of 10 primary ATC cases based on whole exome sequencing. Breakpoints were defined as a change in copy number state. A large number of breakpoints in centromeric regions were seen. (b) Heat map of copy number aberrations in 10 primary ATC cases. Polyploidy and large variations in chromosomal copy number were seen. (c) Expression of genes in amplified regions in all ATC cases and normal thyroid tissue.

High-level amplifications, defined as a gain of more than three extra copies over the baseline level, were seen in eight of ten (80\%) cases, with recurrent amplifications in $19 q 12$ and $19 q 13$ 
(Table S1). The 19q12 amplification was seen in three cases (30\%) with the minimally gained region chr19:30020714-30649335, including the POP4, PLEKHF1, C19orf12, CCNE1, and URI1 genes. All of these genes were highly expressed in the cases with amplification as compared to cases without amplification (Figure 1c). In addition, one of the cases where no copy number analysis had been performed displayed high expression for all of these genes. Furthermore, two cases (20\%) had 19q13 amplifications, with the minimally gained region chr19:36494128-36585117, including the ALKBH6, CLIP3, and THAP8 genes. Of these, only CLIP3 showed increased expression in cases with the amplification (Figure 1c). Among the amplifications that were only seen in single cases, case 2 had an amplification in 7q21 with the minimally gained region chr7:91974285-92987750, including the GATAD1, PEX1, RBM48, FAM133B, CDK6, SAMD9, SAMD9L, and HEPACAM2 genes. All of these genes, except for $S A M D 9, S A M D 9 L$ and HEPACAM2, were highly expressed in this case (Figure 1c). Furthermore, case 2 had an amplification of chr7:18330180-19461461, including TWIST1, which was highly expressed in this case (Figure 1c).

\subsection{Multiple Non-Recurrent Fusion Genes in ATC}

A total of 21 fusion genes were identified in 5/12 cases that were investigated with RNA-seq (Table 2). Of these, 15 were seen in case 5 , whereas cases 3 and 7 had two fusion genes each and cases 12 and 14 had one fusion gene each. Nine of the fusion genes were in-frame and twelve out-of-frame. None of the fusion genes were recurrent, but $F N 1$ was involved in two different out-of-frame fusions. For MLXIP/PTEN and EP400/NCOR2 fusion genes, the reciprocal PTEN/MLXIP and NCOR2/EP400 fusions, respectively, were seen; no other reciprocal fusions were detected.

Table 2. Fusion genes detected in twelve cases of primary anaplastic thyroid cancer.

\begin{tabular}{|c|c|c|c|c|c|}
\hline Case & Fusion Gene & Chromosome & $\begin{array}{c}\text { Inframe/ } \\
\text { Frame-Shift }\end{array}$ & $\begin{array}{c}\text { Software Identifying } \\
\text { Fusion }\end{array}$ & Validated \\
\hline 3 & BGN/THOC7 & Xq28/3p14.1 & Inframe & FusionCatcher & Not done \\
\hline 3 & POSTN/EIF3A & 13q13.3/10q26.11 & Frame-shift & InFusion & Not done \\
\hline 5 & $\begin{array}{l}E P 400 / N C O R 2 \\
\text { NCOR2/EP400 }\end{array}$ & $12 \mathrm{q} 24.33 / 12 \mathrm{q} 24.31$ & Inframe & FusionCatcher & Not done \\
\hline 5 & FN1/PABPC1 & $2 q 35 / 8 q 22.3$ & Frame-shift & FusionCatcher & Not done \\
\hline 5 & IVNS1ABP/KYNU & $1 q 25.3 / 2 q 22.2$ & Inframe & FusionCatcher & Not done \\
\hline 5 & MYH9/EIF2AK3 & $22 \mathrm{q} 12.3 / 2 \mathrm{p} 11.2$ & Frame-shift & FusionCatcher & Not done \\
\hline 5 & PRPF6/TENM3 & $20 q 13.33 / 4 q 35.1$ & Inframe & FusionCatcher & Not done \\
\hline 5 & $R A B 23 / D S T$ & 6p11.2/6p11.2 & Inframe & FusionCatcher & Not done \\
\hline 5 & MYH3/FZD4 & $17 \mathrm{p} 13.1 / 11 \mathrm{q} 14.2$ & Inframe & InFusion & Not done \\
\hline 5 & TAOK1/NME6 & $17 \mathrm{q} 11.2 / 3 \mathrm{p} 21.31$ & Inframe & InFusion & Not done \\
\hline 5 & CNTN1/CCZ1B & $12 \mathrm{q} 12 / 7 \mathrm{p} 22.1$ & Frame-shift & InFusion & Not done \\
\hline 5 & HELZ/MYH10 & $17 q 24.2 / 17 \mathrm{p} 13.1$ & Inframe & InFusion & Not done \\
\hline 5 & VSIG4/TRA2B & Xq12/3q27.2 & Frame-shift & InFusion & Not done \\
\hline 5 & OPHN1/PTRF & $\mathrm{Xq} 12 / 17 \mathrm{q} 21.2$ & Frame-shift & InFusion & Not done \\
\hline 5 & SDC2/SRRT & $8 q 22.1 / 7 q 22.1$ & Frame-shift & InFusion & Not done \\
\hline 5 & HTRA1/AMZ2 & $10 \mathrm{q} 26.13 / 17 \mathrm{q} 24.2$ & Frame-shift & InFusion & Not done \\
\hline 5 & GPR107/MYH10 & $9 q 34.11 / 17 \mathrm{p} 13.1$ & Inframe & InFusion & Not done \\
\hline 7 & MXI1/STMN1 & $10 \mathrm{q} 25.2 / 1 \mathrm{p} 36.11$ & Frame-shift & FusionCatcher & Not done \\
\hline 7 & USP46/FN1 & $4 \mathrm{q} 12 / 2 \mathrm{q} 35$ & Frame-shift & FusionCatcher & Not done \\
\hline 12 & ENO2/PIEZO2 & 12p13.31/18p11.21 & Frame-shift & InFusion & Not done \\
\hline 14 & $\begin{array}{l}\text { MLXIP/PTEN } \\
P T E N / M L X I P\end{array}$ & $12 \mathrm{q} 24.31 / 10 \mathrm{q} 23.31$ & Inframe & FusionCatcher & Yes \\
\hline
\end{tabular}

\subsection{Somatic Mutations in ATC}

WES detected a total of 7478 somatic coding mutations in the eight cases with matched normal samples for analysis, with a median of 60 mutations per case (range 28-6863) (Table S2). Excluding case 12, which had 6863 mutations, the remaining ten cases had a median of 52 mutations per case (range 28-247). For the three cases with no matched normal, a total of 245 mutations remained after filtering, with a median of 87 mutations per case (range 58-99) (Table S3). The most commonly mutated gene was TP53 (6/11 cases; $55 \%$ ), followed by mutations in the TERT promoter (four cases; $36 \%$ ), ATM (three cases; 27\%), and ARID2, BRAF, FANCA, INPP4B, MAP3K1, NF2, PIK3CA, RB1, SMARCA4, and 
TET2 (two cases each; 18\%) (Figure 2, Tables S2 and S3). Furthermore, single cases (9\%) had mutations in NRAS and HRAS (Figure 2, Tables S2 and S3). In addition, case 12 displayed a mutation in CCNE1, which was classified as "tolerated" by SIFT and "benign" by PolyPhen2; it is thus not clear whether this had a pathogenetic effect.

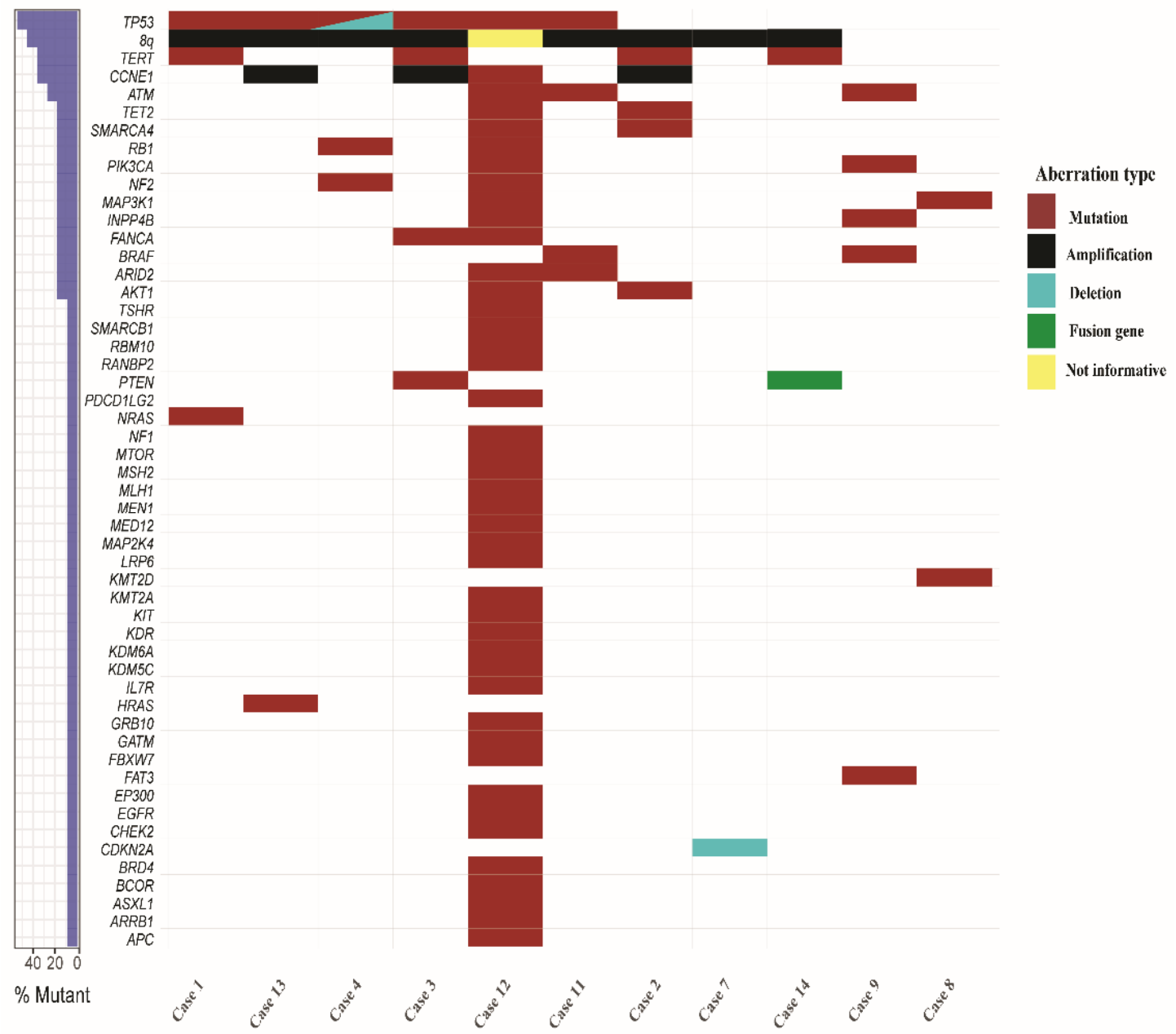

Figure 2. Genomic landscape of 11 cases of anaplastic thyroid cancer investigated by whole exome sequencing.

\subsection{Associations Between Genetic Aberrations and Clinical Parameters}

To see whether the genetic aberrations were associated with any clinical parameters, we performed Fisher's exact two-sided test for the recurrent abnormalites that are listed in Figure 2 vs. nodal stage and presence of distant metastases. No significant associations were detected.

\subsection{Mutational Signatures in ATC}

The analysis of mutational signatures could be performed in all 11 cases that were subjected to WES. The most common mutational signature was 1A/B, associated with aging, seen in six cases (55\%; Figure S1). Five cases (45\%) displayed signature 6, associated with defective DNA mismatch repair, four $(36 \%)$ displayed signatures 2 or 13, associated with activity of the AID/APOBEC family of cytidine deaminases, four (36\%) displayed signature 3, associated with failure of DNA double-strand break-repair by homologous recombination, four (36\%) displayed signature 4 , associated with tobacco exposure, three $(27 \%)$ displayed signature 7 , associated with ultraviolet light exposure, and two (18\%) displayed signature 11, associated with exposure to alkylating agents (Figure S1, https: / / cancer.sanger. ac.uk/cosmic/signatures). Furthermore, case 12 displayed signature 14, which is associated with very 
high numbers of somatic mutations. Additionally, signature 17, which was of unknown etiology, was seen in five cases $(45 \%)$.

\subsection{Microsatellite Instability Is Rare in ATC}

WES data was analyzed to check whether ATC exhibited microsatellite instability (MSI). Only one $(9 \%)$ of the eleven cases had a value that was close to the cut-off for MSI (Figure 3). Notably, this case (\#12) also had mutations in MLH1 and MSH2.

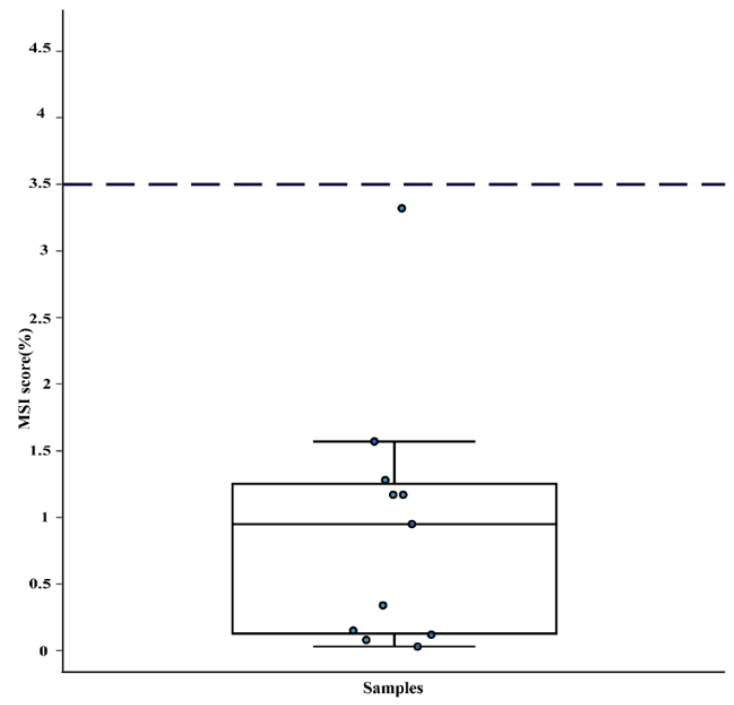

Figure 3. Microsatellite instability (MSI) scores for 11 anaplastic thyroid cancer cases. The dotted line represents the threshold to classify a case as MSI positive. Only one case was borderline MSI positive.

\section{Discussion}

In spite of ATC being one of the most fatal malignancies, its genetic background has not yet been fully explored. Here, we present data on copy number, fusion genes, and mutations from fourteen primary ATC samples, obtained before chemo- or radiotherapy.

Copy number analysis was done based on WES, providing a variable resolution across the genome depending on gene density. In line with previous studies using chromosome banding and aCGH [5-11], we found that at least 7/10 (70\%) tumors were polyploid based on variable copy number and VAF. Furthermore, a high frequency of breakpoints in the centromeric regions were seen, similar to what we have previously reported in the ATC cell lines [26]. This has been proposed to be a sign of chromosomal instability that can arise either due to the formation of breakage-fusion-bridge cycles that are caused by telomere dysfunction or due to mitotic spindle defects $[27,28]$. On the chromosomal level, most of the chromosomes displayed variable copy numbers between cases. The exception was chromosome 8 , which showed a loss of $8 p$ relative to the baseline copy number in 6/10 (60\%) cases and gain of $8 q$ in $8 / 10$ cases $(80 \%)$. Thus, it is likely that a gain of $8 q$ is a driver event in ATC; however, since this is a large region containing $>1500$ genes, it was not possible to identify the target gene(s).

A relatively high number of amplifications was seen. Three cases (\#2,\#3, and \#13) harbored amplification of 19q12 with CCNE1 as the putative target gene. CCNE1 promotes progression into the S phase of the cell cycle by interacting with cyclin dependent kinases (CDKs) [29]. CCNE1 amplifications were recently reported in ATC [17] and they are known to occur in multiple malignancies, including ovarian, breast, and gastric cancer [30-33]. Apart from being highly expressed in all cases with the amplification, one additional case (\#5) without copy number data displayed high expression of CCNE1 and also likely had amplification. Furthermore, case 12 displayed a somatic mutation in CCNE1. However, this was classified as non-pathogenic and possibly a passenger event. Thus, in total, 4/14 (29\%) of our cases displayed an amplification of CCNE1; a frequency much higher than the $4 \%$ of cases 
that were reported by Pozdeyev et al. [17], although this difference could be due to the small size of our cohort. Interestingly, one of our cases (\#2) also had the amplification and overexpression of CDK6, active in the same cellular processes as CCNE1 [34]. Although there are no drugs that are available that specifically targets CCNE1, multiple inhibitors for CDKs are under development and could be viable treatment options in CCNE1- and CDK6-amplified ATC [29,35].

Amplification of TWIST1 was seen in case 2. TWIST1 is a transcription factor that is involved in the epithelial-to-mesenchymal transition (EMT) pathway and it is frequently overexpressed in cancer [36]. Preclinical studies in mouse models of KRAS-mutant lung cancer suggest that harmine, a $\beta$-carboline alkaloid, can be used to target TWIST1 with high efficacy [37].

A total of 21 fusion genes were identified, none of which were recurrent. There was a large variation in the number of fusion genes detected per case, with case 5 displaying 16 fusion genes and the remaining eleven cases investigated with RNA-seq having 0-2 fusion genes (Table 2). This is similar to what we have previously reported in ATC cell lines [26], and suggest that a large proportion of the fusion genes detected may be passenger events resulting from chromosomal breaks. Notably, FN1 was involved in two different fusion genes-a FN1/PABPC1 in case 5 and a USP46/FN1 in case 7. FN1 is a component of the extracellular matrix and it is recurrently involved in in-frame fusion genes as the $5^{\prime}$ partner in FN1-ALK and FN1-FGFR1 in soft tissue tumors [38,39]. However, the FN1 fusions that were detected here were both out-of-frame and therefore likely to result in a loss of the normal function of FN1. Furthermore, one case harbored an in-frame PTEN/MLXIP fusion, which has not been previously reported. PTEN is a well-known tumor suppressor gene that regulates the PI3K/AKT pathway [40]. Both in-frame and out-of-frame PTEN fusion genes have been reported to occur at a low frequency in various malignancies; the pathogenetic outcome is generally considered to be the loss of normal PTEN function [41-43].

The pattern of somatic mutations found in our study was similar to what has been previously reported [13-23]. An analysis of mutational signatures showed a high incidence ( $>30 \%$ of cases) of processes that are involved with normal aging, defective DNA mismatch repair, AID/APOBEC activity, failure of DNA double-strand break repair, and tobacco exposure. This agrees well with the results from Pozdeyev et al. [17], who reported that defective DNA mismatch repair and the activation of AID/APOBEC was common in ATC, based on targeted sequencing data from 24 cases, and also with the data from Dong et al. [24] from WES in five cases. Taken together, though, the mutational processes occurring in ATC appear to differ between cases (Figure S1), suggesting different underlying etiologies.

Case 12 was an outlier in terms of having a much higher number of somatic mutations (6863 vs. a median of 52 for the remaining cases), as well as occurring in a relatively young (49 years) patient. This case also showed a borderline value for microsatellite instability and it had mutations in both MLH1 and MSH2, involved in DNA mismatch repair (Figures 2 and 3). Notably, case 12 also exhibited mutational signature 14, which was recently shown to be caused by a combination of loss of polymerase proofreading due to mutations in POLE or POLD1 and defective mismatch repair [44]; in line with this, case 12 had two mutations in POLE (Table S2). Microsatellite instability has been proposed to be a marker for a favorable response to PD1 blockade therapy [45]; thus, this treatment could have been a viable therapeutic option for this patient.

Pozdeyev et al. [17] recently suggested that ATC may be divided into three different subtypes that are based on the mutational pattern: (1) tumors with BRAF V600E mutations, together with PIK3CA, AKT1 or ARID2 mutations, (2) tumors with NRAS mutations and CCNE1 amplification, and (3) tumors with a high mutational burden and MSH2/MLH1 mutations. In our cohort, cases 9 and 11 could be classified as type 1 according to this system based on having concurrent BRAF V600E and ARID2/PIK3CA mutations. Cases 2, 3, 5, and 13 had CCNE1 amplification corresponding to type 2, none of which had NRAS mutation, whereas case 1 had an NRAS mutation; all of these could tentatively be classified as type 2 . Finally, case 12 had a very high number of somatic mutations $(n=6863)$ and mutations in both $M S H 2 / M L H 1$, agreeing well with type 3 . The remaining cases could not be classified as either of these types based on the mutations. 
Taken together, we show that a relatively large proportion (5/14 cases; $36 \%$ ) of ATC harbor genetic events that make them suitable for novel therapeutic approaches, including CDK and TWIST1 inhibition, as well as PD1 blockade therapy. When considering the dismal prognosis of this disease, this should be addressed in future clinical trials.

\section{Material and Methods}

\subsection{Patient Samples}

The study initially included a total of 23 cases of ATC, which were selected on the basis of not having obtained chemo- or radiotherapy treatment prior to sampling, as well as on sample availability. Twenty-two formalin-fixed, paraffin-embedded (FFPE) samples with hematoxylin and eosin stained tumor sections were obtained from the Pathology Department, Laboratory Medicine, Skåne, Sweden. Furthermore, a fine-needle aspirate that was obtained at ATC diagnosis and a paired peripheral blood sample was included from one additional patient (case 1). A pathologist reviewed all of the FFPE blocks to confirm the presence of ATC and to determine tumor cell content. Cases with $<30 \%$ tumor cells based on the pathologist's estimate $(n=5)$, and cases with no copy number aberrations or mutations that were detected by WES $(n=4)$ were excluded from further analyses, leaving 14 cases (Table 1$)$. Three $10 \mu \mathrm{m}$ sections were cut from each tumor and parts containing tumor and adjacent normal tissue were manually microdissected when possible. Sections were immediately put in deparaffinization solution (Qiagen, Valencia, CA, USA), followed by DNA and RNA extraction with the all prep DNA/RNA FFPE Kit (Qiagen), according to the manufacturer's recommendations. For the fine needle aspirate and the matching peripheral blood sample, DNA and RNA extractions were performed with the all prep DNA/RNA kit (Qiagen), according to the manufacturer's recommendations. The Ethical Review Board of Lund University approved the study (No. 2016/51, 1 February 2016).

\subsection{Whole Exome Sequencing}

WES was performed on eight matched tumor-normal samples and three tumor samples without matching normal samples (Table 1). DNA damage that was caused by formaldehyde fixation was repaired with the PreCR Repair Mix (New England Biolabs, Ipswich, MA, USA) according to the manufacturer's recommendations. Genomic DNA was sheared via sonication while using an S220 focused-ultrasonicator (Covaris, Woburn, MA, USA) and DNA libraries were constructed using the TruSeq Exome Kit (Illumina, San Diego, CA, USA), according to the manufacturer's recommendations. The libraries were sequenced using the High Output Kit (150 cycles) on a NextSeq500 (Illumina). Raw reads were aligned to the human reference genome hy19 with the BWA-MEM algorithm [46]. Picard (http:/ / broadinstitute.github.io/picard) was used to remove the PCR duplicates and local realignment around the indel region was performed using GATK [47]. Copy number aberrations were identified by cnvkit [48] and manually annotated; the resulting data from case 12 were too noisy for interpretation, and this case was hence excluded from copy number analysis. For cases with matched normal samples, the somatic mutations were identified using MuTect2 [49] with default settings. For tumor samples without matched normal samples, variations were identified by GATK Unified Genotyper and annotation parameters QD (variant confidence/quality by depth) <2.0, MQ (root mean square mapping quality) < 40.0, FS (Fisher strand) 60.0, HaploTypeScore $>13.0$, MQRankSum $<-12.5$, and ReadPosRankSum $<-8.0$ were used to filter the low quality variations [50]. High quality variants were further filtered by 1000 Genomes (20110521 release), ESP6500, ExAC, CG46 (popfreq_max_20150413), and 170 million variants (kaviar_20150923) provided by ANNOVAR [51] to remove the potential SNP sites. Annotation of variants were carried out with ANNOVAR [51]. The lists of somatic mutations were further filtered for a minimum coverage of 15 reads, keeping only non-synonymous mutations that were supported by $\geq 5$ reads and a mutant allele frequency of $\geq 5 \%$. Mutation signatures were identified with DeconstructSigs [52]. The genomic landscape plot was generated using GenVisR [53]. 
MSIsensor [54] was used for analyzing microsatellite instability. Only heteropolymer sites were included in this analysis.

\subsection{RNA Sequencing}

RNA-seq was performed on 12 primary ATC cases (Table 1) and normal tissue from four thyroids. For the tumor cases, the quantity and purity of RNA was measured with NanoDrop (Thermo Fisher Scientific, Waltham, MA, USA) and the quality on a 2100 Bioanalyzer (Agilent Technologies, Palo Alto, CA, USA) to check for the fraction of RNA fragments that were greater than $200 \mathrm{nt}$ (Dv200). mRNA libraries were constructed with an input of 20-50 ng of RNA, depending on the Dv200 value using the TruSeq RNA Access Library Prep Kit (Illumina), according to the manufacturer's recommendations. Constructed libraries were sequenced using Illumina's High Output Kit (150 cycles) on an Illumina NextSeq500. Identifications of fusion transcripts were performed using FusionCatcher [55] and InFusion [56] from raw fastq files. The list of fusion genes was filtered to remove chimeras that were identified as read-through transcripts, pseudogenes, unannotated genes, and fusions between gene family members, as well as by keeping only fusions that had unique spanning reads $\geq 3$ (FusionCatcher) and $\geq 20$ (InFusion). For expression analysis, RNA sequencing data were processed using the TCGA mRNA-seq pipeline (https:/ / docs.gdc.cancer.gov/Data/Bioinformatics_Pipelines/ Expression_mRNA_Pipeline/\#mrna-analysis-pipeline). Briefly, the sequencing reads were aligned to the human GRCh38 genome assembly using STAR [57] and the read counts for each gene were obtained using HTSeq-count [58] and they were normalized using the fragments per kilobase of exon model per million mapped reads (FPKM) method. For fusion gene validation, RT-PCR was performed in case 14, which was the only case where cDNA could be obtained. Briefly, cDNA was synthesized while using High-Capacity cDNA Reverse Transcription Kit (Thermo Fisher Scientific) and SuperScript IV First-Strand Synthesis System (Thermo Fisher Scientific). Primers (available on request) were designed using Primer 3 (http:/ / primer3.ut.ee/) specifically for the fusion transcript. PCR was performed according to standard methods and Eurofins Genomics sequenced the amplified products (Ebersberg, Germany).

\subsection{Analysis of TERT Promoter Mutations}

TERT promoter mutations were investigated according to Liu et al. [59] using the AmpliTaq Gold 360 Master Mix (Thermo Fisher Scientific).

\subsection{Statistical Analysis}

Fisher's two-sided exact test was used to investigate whether any of the detected genetic aberrations were associated with clinical parameters. Since all cases were T4, stage IV, and had high Ki67, this analysis could only be done for nodal stage and the presence of distant metastases.

\section{Conclusions}

In conclusion, we have performed a full-scale genomic analysis of primary ATC, showing complex copy number aberrations and polyploidy, multiple fusion genes, and a high level of mutations. A high proportion of the investigated cases were found to be candidates for novel treatments, showing that genomic analyses are highly clinically valuable in ATC.

Supplementary Materials: The following are available online at http:/ /www.mdpi.com/2072-6694/11/3/402/s1, Figure S1: Mutation signatures of 11 primary anaplastic thyroid cancer cases, showing heterogeneity in the involved mutational processes. Table S1: Copy number aberrations detected by whole exome sequencing in 10 cases of anaplastic thyroid cancer, Table S2: Somatic mutations detected in 8 paired tumor/normal samples of anaplastic thyroid cancer, Table S3: Somatic mutations detected in 3 cases of anaplastic thyroid cancer lacking a matched normal sample. 
Author Contributions: Conceptualization, L.E., J.W. and K.P.; Investigation, N.R., C.J., N.M., S.R.S. and E.L.W.; Formal Analysis, N.R. and M.Y., Resources, S.G., L.E. and J.W.; Writing-Original Draft Preparation, N.R. and K.P.; Writing-Review and Editing, all authors; Supervision, K.P.; Funding Acquisition, K.P.

Funding: This research was funded by the Swedish Research Council, grant number 2016-01459, the Swedish Cancer Society, grant number 2016/497, the Royal Physiographic Society of Lund, grant number 37363, the Crafoord Foundation, grant number 20170503, and BioCare Lund.

Acknowledgments: The authors thank David Gisselsson Nord for help with pathological assessment.

Conflicts of Interest: The authors declare no conflict of interest.

\section{References}

1. O'Neill, J.P.; Shaha, A.R. Anaplastic thyroid cancer. Oral Oncol. 2013, 49, 702-706. [CrossRef] [PubMed]

2. Molinaro, E.; Romei, C.; Biagini, A.; Sabini, E.; Agate, L.; Mazzeo, S.; Materazzi, G.; Sellari-Franceschini, S.; Ribechini, A.; Torregrossa, L.; et al. Anaplastic thyroid carcinoma: From clinicopathology to genetics and advanced therapies. Nat. Rev. Endocrinol. 2017, 13, 644-660. [CrossRef]

3. Kebebew, E.; Greenspan, F.S.; Clark, O.H.; Woeber, K.A.; McMillan, A. Anaplastic thyroid carcinoma. Treatment outcome and prognostic factors. Cancer 2005, 103, 1330-1335. [CrossRef] [PubMed]

4. Glaser, S.M.; Mandish, S.F.; Gill, B.S.; Balasubramani, G.K.; Clump, D.A.; Beriwal, S. Anaplastic thyroid cancer: Prognostic factors, patterns of care, and overall survival. Head Neck 2016, 38, E2083-E2090. [CrossRef] [PubMed]

5. Bol, S.; Belge, G.; Thode, B.; Bonk, U.; Bartnitzke, S.; Bullerdiek, J. Cytogenetic tetraclonality in a rare spindle cell variant of an anaplastic carcinoma of the thyroid. Cancer Genet. Cytogenet. 2001, 125, 163-166. [CrossRef]

6. Roque, L.; Soares, J.; Castedo, S. Cytogenetic and fluorescence in situ hybridization studies in a case of anaplastic thyroid carcinoma. Cancer Genet. Cytogenet. 1998, 103, 7-10. [CrossRef]

7. Mark, J.; Ekedahl, C.; Dahlenfors, R.; Westermark, B. Cytogenetical observations in five human anaplastic thyroid carcinomas. Hereditas 1987, 107, 163-174. [CrossRef] [PubMed]

8. Jenkins, R.B.; Hay, I.D.; Herath, J.F.; Schultz, C.G.; Spurbeck, J.L.; Grant, C.S.; Goellner, J.R.; Dewald, G.W. Frequent occurrence of cytogenetic abnormalities in sporadic nonmedullary thyroid carcinoma. Cancer 1990, 66, 1213-1220. [CrossRef]

9. Wreesmann, V.B.; Ghossein, R.A.; Patel, S.G.; Harris, C.P.; Schnaser, E.A.; Shaha, A.R.; Tuttle, R.M.; Shah, J.P.; Rao, P.H.; Singh, B. Genome-wide appraisal of thyroid cancer progression. Am. J. Pathol. 2002, 161, 1549-1556. [CrossRef]

10. Miura, D.; Wada, N.; Chin, K.; Magrane, G.G.; Wong, M.; Duh, Q.Y.; Clark, O.H. Anaplastic thyroid cancer: Cytogenetic patterns by comparative genomic hybridization. Thyroid 2003, 13, 283-290. [CrossRef]

11. Lee, J.J.; Foukakis, T.; Hashemi, J.; Grimelius, L.; Heldin, N.E.; Wallin, G.; Rudduck, C.; Lui, W.O.; Hoog, A.; Larsson, C. Molecular cytogenetic profiles of novel and established human anaplastic thyroid carcinoma models. Thyroid 2007, 17, 289-301. [CrossRef] [PubMed]

12. Kelly, L.M.; Barila, G.; Liu, P.; Evdokimova, V.N.; Trivedi, S.; Panebianco, F.; Gandhi, M.; Carty, S.E.; Hodak, S.P.; Luo, J.; et al. Identification of the transforming STRN-ALK fusion as a potential therapeutic target in the aggressive forms of thyroid cancer. Proc. Natl. Acad. Sci. USA 2014, 111, 4233-4238. [CrossRef] [PubMed]

13. Tiedje, V.; Ting, S.; Herold, T.; Synoracki, S.; Latteyer, S.; Moeller, L.C.; Zwanziger, D.; Stuschke, M.; Fuehrer, D.; Schmid, K.W. NGS based identification of mutational hotspots for targeted therapy in anaplastic thyroid carcinoma. Oncotarget 2017, 8, 42613-42620. [CrossRef] [PubMed]

14. Jeon, M.J.; Chun, S.M.; Kim, D.; Kwon, H.; Jang, E.K.; Kim, T.Y.; Kim, W.B.; Shong, Y.K.; Jang, S.J.; Song, D.E.; et al. Genomic alterations of anaplastic thyroid carcinoma detected by targeted massive parallel sequencing in a BRAF(V600E) mutation-prevalent area. Thyroid 2016, 26, 683-690. [CrossRef] [PubMed]

15. Nikiforova, M.N.; Wald, A.I.; Roy, S.; Durso, M.B.; Nikiforov, Y.E. Targeted next-generation sequencing panel (ThyroSeq) for detection of mutations in thyroid cancer. J. Clin. Endocrinol. Metab. 2013, 98, E1852-E1860. [CrossRef] [PubMed]

16. Gibson, W.J.; Ruan, D.T.; Paulson, V.A.; Barletta, J.A.; Hanna, G.J.; Kraft, S.; Calles, A.; Nehs, M.A.; Moore, F.D., Jr.; Taylor-Weiner, A.; et al. Genomic heterogeneity and exceptional response to dual pathway inhibition in anaplastic thyroid cancer. Clin. Cancer Res. 2017, 23, 2367-2373. [CrossRef] [PubMed] 
17. Pozdeyev, N.; Gay, L.M.; Sokol, E.S.; Hartmaier, R.; Deaver, K.E.; Davis, S.; French, J.D.; Borre, P.V.; LaBarbera, D.V.; Tan, A.C.; et al. Genetic analysis of 779 advanced differentiated and anaplastic thyroid cancers. Clin. Cancer Res. 2018, 24, 3059-3068. [CrossRef] [PubMed]

18. Ibrahimpasic, T.; Xu, B.; Landa, I.; Dogan, S.; Middha, S.; Seshan, V.; Deraje, S.; Carlson, D.L.; Migliacci, J.; Knauf, J.A.; et al. Genomic alterations in fatal forms of non-anaplastic thyroid cancer: Identification of MED12 and RBM10 as novel thyroid cancer genes associated with tumor virulence. Clin. Cancer Res. 2017, 23, 5970-5980. [CrossRef] [PubMed]

19. Latteyer, S.; Tiedje, V.; Konig, K.; Ting, S.; Heukamp, L.C.; Meder, L.; Schmid, K.W.; Fuhrer, D.; Moeller, L.C. Targeted next-generation sequencing for TP53, RAS, BRAF, ALK and NF1 mutations in anaplastic thyroid cancer. Endocrine 2016, 54, 733-741. [CrossRef]

20. Capdevila, J.; Mayor, R.; Mancuso, F.M.; Iglesias, C.; Caratu, G.; Matos, I.; Zafon, C.; Hernando, J.; Petit, A.; Nuciforo, P.; et al. Early evolutionary divergence between papillary and anaplastic thyroid cancers. Ann. Oncol. 2018, 29, 1454-1460. [CrossRef] [PubMed]

21. Kunstman, J.W.; Juhlin, C.C.; Goh, G.; Brown, T.C.; Stenman, A.; Healy, J.M.; Rubinstein, J.C.; Choi, M.; Kiss, N.; Nelson-Williams, C.; et al. Characterization of the mutational landscape of anaplastic thyroid cancer via whole-exome sequencing. Hum. Mol. Genet. 2015, 24, 2318-2329. [CrossRef] [PubMed]

22. Landa, I.; Ibrahimpasic, T.; Boucai, L.; Sinha, R.; Knauf, J.A.; Shah, R.H.; Dogan, S.; Ricarte-Filho, J.C.; Krishnamoorthy, G.P.; Xu, B.; et al. Genomic and transcriptomic hallmarks of poorly differentiated and anaplastic thyroid cancers. J. Clin. Investig. 2016, 126, 1052-1066. [CrossRef] [PubMed]

23. de Biase, D.; Torricelli, F.; Ragazzi, M.; Donati, B.; Khun, E.; Visani, M.; Acquaviva, G.; Pession, A.; Tallini, G.; Piana, S.; et al. Not the same thing: Metastatic PTCs have a different background than ATCs. Endocr. Connect. 2018, 7. [CrossRef] [PubMed]

24. Dong, W.; Nicolson, N.G.; Choi, J.; Barbieri, A.L.; Kunstman, J.W.; Abou Azar, S.; Knight, J.; Bilguvar, K.; Mane, S.M.; Lifton, R.P.; et al. Clonal evolution analysis of paired anaplastic and well-differentiated thyroid carcinomas reveals shared common ancestor. Genes Chromosomes Cancer 2018, 57, 645-652. [CrossRef]

25. Sobin, L.H.; Gospodarowics, M.K. International union against cancer (UICC). In TNM Classification of Malignant Tumours, 7th ed.; Wittekind, C., Ed.; John Wiley \& Sons: New York, NY, USA, 2009.

26. Woodward, E.L.; Biloglav, A.; Ravi, N.; Yang, M.; Ekblad, L.; Wennerberg, J.; Paulsson, K. Genomic complexity and targeted genes in anaplastic thyroid cancer cell lines. Endocr. Relat. Cancer 2017, 24, X2. [CrossRef] [PubMed]

27. Stewenius, Y.; Gorunova, L.; Jonson, T.; Larsson, N.; Hoglund, M.; Mandahl, N.; Mertens, F.; Mitelman, F.; Gisselsson, D. Structural and numerical chromosome changes in colon cancer develop through telomere-mediated anaphase bridges, not through mitotic multipolarity. Proc. Natl. Acad. Sci. USA 2005, 102, 5541-5546. [CrossRef] [PubMed]

28. Guerrero, A.A.; Gamero, M.C.; Trachana, V.; Futterer, A.; Pacios-Bras, C.; Diaz-Concha, N.P.; Cigudosa, J.C.; Martinez, A.C.; van Wely, K.H. Centromere-localized breaks indicate the generation of DNA damage by the mitotic spindle. Proc. Natl. Acad. Sci. USA 2010, 107, 4159-4164. [CrossRef] [PubMed]

29. Kanska, J.; Zakhour, M.; Taylor-Harding, B.; Karlan, B.Y.; Wiedemeyer, W.R. Cyclin E as a potential therapeutic target in high grade serous ovarian cancer. Gynecol. Oncol. 2016, 143, 152-158. [CrossRef] [PubMed]

30. Luhtala, S.; Staff, S.; Tanner, M.; Isola, J. Cyclin E amplification, over-expression, and relapse-free survival in HER-2-positive primary breast cancer. Tumour Biol. 2016, 37, 9813-9823. [CrossRef]

31. Zhao, Z.M.; Yost, S.E.; Hutchinson, K.E.; Li, S.M.; Yuan, Y.C.; Noorbakhsh, J.; Liu, Z.; Warden, C.; Johnson, R.M.; Wu, X.; et al. CCNE1 amplification is associated with poor prognosis in patients with triple negative breast cancer. BMC Cancer 2019, 19, 96. [CrossRef] [PubMed]

32. Zhou, Z.; Bandla, S.; Ye, J.; Xia, Y.; Que, J.; Luketich, J.D.; Pennathur, A.; Peters, J.H.; Tan, D.; Godfrey, T.E. Cyclin E involved in early stage carcinogenesis of esophageal adenocarcinoma by SNP DNA microarray and immunohistochemical studies. BMC Gastroenterol. 2014, 14, 78. [CrossRef] [PubMed]

33. Etemadmoghadam, D.; deFazio, A.; Beroukhim, R.; Mermel, C.; George, J.; Getz, G.; Tothill, R.; Okamoto, A.; Raeder, M.B.; Harnett, P.; et al. Integrated genome-wide DNA copy number and expression analysis identifies distinct mechanisms of primary chemoresistance in ovarian carcinomas. Clin. Cancer Res. 2009, 15, 1417-1427. [CrossRef] [PubMed] 
34. Tigan, A.S.; Bellutti, F.; Kollmann, K.; Tebb, G.; Sexl, V. CDK6-a review of the past and a glimpse into the future: From cell-cycle control to transcriptional regulation. Oncogene 2016, 35, 3083-3091. [CrossRef] [PubMed]

35. Asghar, U.; Witkiewicz, A.K.; Turner, N.C.; Knudsen, E.S. The history and future of targeting cyclin-dependent kinases in cancer therapy. Nat. Rev. Drug Discov. 2015, 14, 130-146. [CrossRef] [PubMed]

36. Zhao, Z.; Rahman, M.A.; Chen, Z.G.; Shin, D.M. Multiple biological functions of Twist1 in various cancers. Oncotarget 2017, 8, 20380-20393. [CrossRef] [PubMed]

37. Yochum, Z.A.; Cades, J.; Mazzacurati, L.; Neumann, N.M.; Khetarpal, S.K.; Chatterjee, S.; Wang, H.; Attar, M.A.; Huang, E.H.; Chatley, S.N.; et al. A First-in-Class TWIST1 Inhibitor with Activity in Oncogene-Driven Lung Cancer. Mol. Cancer Res. 2017, 15, 1764-1776. [CrossRef]

38. Lee, J.C.; Su, S.Y.; Changou, C.A.; Yang, R.S.; Tsai, K.S.; Collins, M.T.; Orwoll, E.S.; Lin, C.Y.; Chen, S.H.; Shih, S.R.; et al. Characterization of FN1-FGFR1 and novel FN1-FGF1 fusion genes in a large series of phosphaturic mesenchymal tumors. Mod. Pathol. 2016, 29, 1335-1346. [CrossRef] [PubMed]

39. Ouchi, K.; Miyachi, M.; Tsuma, Y.; Tsuchiya, K.; Iehara, T.; Konishi, E.; Yanagisawa, A.; Hosoi, H. FN1: A novel fusion partner of ALK in an inflammatory myofibroblastic tumor. Pediatr. Blood Cancer 2015, 62, 909-911. [CrossRef] [PubMed]

40. Milella, M.; Falcone, I.; Conciatori, F.; Cesta Incani, U.; Del Curatolo, A.; Inzerilli, N.; Nuzzo, C.M.; Vaccaro, V.; Vari, S.; Cognetti, F.; et al. PTEN: Multiple Functions in Human Malignant Tumors. Front. Oncol. 2015, 5, 24. [CrossRef]

41. Hu, X.; Wang, Q.; Tang, M.; Barthel, F.; Amin, S.; Yoshihara, K.; Lang, F.M.; Martinez-Ledesma, E.; Lee, S.H.; Zheng, S.; et al. TumorFusions: An integrative resource for cancer-associated transcript fusions. Nucleic Acids Res. 2018, 46, D1144-D1149. [CrossRef]

42. Robinson, D.R.; Wu, Y.M.; Lonigro, R.J.; Vats, P.; Cobain, E.; Everett, J.; Cao, X.; Rabban, E.; Kumar-Sinha, C.; Raymond, V.; et al. Integrative clinical genomics of metastatic cancer. Nature 2017, 548, 297-303. [CrossRef]

43. Northcott, P.A.; Buchhalter, I.; Morrissy, A.S.; Hovestadt, V.; Weischenfeldt, J.; Ehrenberger, T.; Grobner, S.; Segura-Wang, M.; Zichner, T.; Rudneva, V.A.; et al. The whole-genome landscape of medulloblastoma subtypes. Nature 2017, 547, 311-317. [CrossRef] [PubMed]

44. Haradhvala, N.J.; Kim, J.; Maruvka, Y.E.; Polak, P.; Rosebrock, D.; Livitz, D.; Hess, J.M.; Leshchiner, I.; Kamburov, A.; Mouw, K.W.; et al. Distinct mutational signatures characterize concurrent loss of polymerase proofreading and mismatch repair. Nat. Commun. 2018, 9, 1746. [CrossRef] [PubMed]

45. Le, D.T.; Durham, J.N.; Smith, K.N.; Wang, H.; Bartlett, B.R.; Aulakh, L.K.; Lu, S.; Kemberling, H.; Wilt, C.; Luber, B.S.; et al. Mismatch repair deficiency predicts response of solid tumors to PD-1 blockade. Science 2017, 357, 409-413. [CrossRef]

46. Li, H.; Durbin, R. Fast and accurate short read alignment with Burrows-Wheeler transform. Bioinformatics 2009, 25, 1754-1760. [CrossRef] [PubMed]

47. McKenna, A.; Hanna, M.; Banks, E.; Sivachenko, A.; Cibulskis, K.; Kernytsky, A.; Garimella, K.; Altshuler, D.; Gabriel, S.; Daly, M.; et al. The genome analysis toolkit: A mapreduce framework for analyzing next-generation DNA sequencing data. Genome Res. 2010, 20, 1297-1303. [CrossRef] [PubMed]

48. Talevich, E.; Shain, A.H.; Botton, T.; Bastian, B.C. CNVkit: Genome-wide copy number detection and visualization from targeted DNA sequencing. PLoS Comput. Biol. 2016, 12, e1004873. [CrossRef]

49. Cibulskis, K.; Lawrence, M.S.; Carter, S.L.; Sivachenko, A.; Jaffe, D.; Sougnez, C.; Gabriel, S.; Meyerson, M.; Lander, E.S.; Getz, G. Sensitive detection of somatic point mutations in impure and heterogeneous cancer samples. Nat. Biotechnol. 2013, 31, 213-219. [CrossRef]

50. Sulem, P.; Helgason, H.; Oddson, A.; Stefansson, H.; Gudjonsson, S.A.; Zink, F.; Hjartarson, E.; Sigurdsson, G.T.; Jonasdottir, A.; Jonasdottir, A.; et al. Identification of a large set of rare complete human knockouts. Nat. Genet. 2015, 47, 448-452. [CrossRef] [PubMed]

51. Wang, K.; Li, M.; Hakonarson, H. ANNOVAR: Functional annotation of genetic variants from high-throughput sequencing data. Nucleic Acids Res. 2010, 38, e164. [CrossRef]

52. Rosenthal, R.; McGranahan, N.; Herrero, J.; Taylor, B.S.; Swanton, C. DeconstructSigs: Delineating mutational processes in single tumors distinguishes DNA repair deficiencies and patterns of carcinoma evolution. Genome Biol. 2016, 17, 31. [CrossRef] [PubMed]

53. Skidmore, Z.L.; Wagner, A.H.; Lesurf, R.; Campbell, K.M.; Kunisaki, J.; Griffith, O.L.; Griffith, M. GenVisR: Genomic visualizations in R. Bioinformatics 2016, 32, 3012-3014. [CrossRef] [PubMed] 
54. Niu, B.; Ye, K.; Zhang, Q.; Lu, C.; Xie, M.; McLellan, M.D.; Wendl, M.C.; Ding, L. MSIsensor: Microsatellite instability detection using paired tumor-normal sequence data. Bioinformatics 2014, 30, 1015-1016. [CrossRef] [PubMed]

55. Nicorici, D.; Satalan, M.; Edgren, H.; Kangaspeska, S.; Murumagi, A.; Kallioniemi, O.; Virtanen, S.; Kilkku, O. FusionCatcher-a tool for finding somatic fusion genes in paired-end RNA-sequencing data. BioRxiv 2014, 011650. [CrossRef]

56. Okonechnikov, K.; Imai-Matsushima, A.; Paul, L.; Seitz, A.; Meyer, T.F.; Garcia-Alcalde, F. InFusion: Advancing Discovery of Fusion Genes and Chimeric Transcripts from Deep RNA-Sequencing Data. PLoS ONE 2016, 11, e0167417. [CrossRef]

57. Dobin, A.; Davis, C.A.; Schlesinger, F.; Drenkow, J.; Zaleski, C.; Jha, S.; Batut, P.; Chaisson, M.; Gingeras, T.R. STAR: Ultrafast universal RNA-seq aligner. Bioinformatics 2013, 29, 15-21. [CrossRef] [PubMed]

58. Anders, S.; Pyl, P.T.; Huber, W. HTSeq-A Python framework to work with high-throughput sequencing data. Bioinformatics 2015, 31, 166-169. [CrossRef] [PubMed]

59. Liu, X.; Bishop, J.; Shan, Y.; Pai, S.; Liu, D.; Murugan, A.K.; Sun, H.; El-Naggar, A.K.; Xing, M. Highly prevalent TERT promoter mutations in aggressive thyroid cancers. Endocr. Relat. Cancer 2013, 20, 603-610. [CrossRef]

(C) 2019 by the authors. Licensee MDPI, Basel, Switzerland. This article is an open access article distributed under the terms and conditions of the Creative Commons Attribution (CC BY) license (http:/ / creativecommons.org/licenses/by/4.0/). 